\title{
Purification of Pili and Outer Membrane Vesicles of Neisseria gonorrhoeae by Wheat Germ Agglutinin Affinity Chromatography
}

\author{
By V. Y. PERERA, C. W. PENN* AND H. SMITH \\ Department of Microbiology, University of Birmingham, P.O. Box 363, \\ Birmingham B15 2TT, U.K.
}

(Received 5 October 1981; revised 16 November 1981)

\begin{abstract}
Previous studies indicated that OMVs of Neisseria gonorrhoeae reacted specifically with WGA. A technique was therefore developed for the separation of gonococcal pili and OMVs by WGA affinity chromatography. This method was more convenient and more effective than isopycnic centrifugation for obtaining OMVs free of pili. The antigens were further purified but though homogeneous as judged by in vitro analytical methods, they both elicited an antibody response in animals to minor impurities previously undetected.
\end{abstract}

\section{INTRODUCTION}

The main particulate antigens released from the surface of Neisseria gonorrhoeae are pili and OMVs. Since immunization of guinea-pigs with crude extracts of surface antigens from certain strains of gonococci conferred protection (Parsons et al., 1979), the immunizing antigens were probably located on the surface of the organisms. Two of the antigens possibly implicated in immunity have been identified as pili (antigen $a$; Penn et al., 1980) and OMVs (antigen c; Perera et al., 1980). Attempts to purify pili and OMVs by published methods (Buchanan, 1975; Johnston et al., 1976) were hampered by the physical heterogeneity of these antigens, and a more discriminating separation method was therefore sought.

The outer membrane of $N$. gonorrhoeae, as in other Gram-negative bacteria, is composed of proteins, LPS and phospholipid, the predominant proteins being the principal outer membrane protein and several heat-modifiable proteins (Johnston \& Gotschlich, 1974; Lambden \& Heckels, 1979). We have shown that OMVs reacted specifically with the lectin WGA (Perera et al., 1980) and the reactive constituent was identified as LPS. The agglutination of gonococci by this lectin, and the reactivity of purified LPS with WGA reported independently by other workers (Schaefer et al., 1979; Allen et al., 1980; Frasch, 1980) substantiated our findings.

Lectin affinity chromatography has been widely used for the purification of glycoproteins from many sources (Hayman et al., 1973; Van Etten \& Saini, 1977; Mintz \& Glaser, 1979; Vretblad \& Hjorth, 1977). This paper describes the application of WGA affinity chromatography as a specific means of separating and purifying OMVs from crude extracts of surface antigens of $N$. gonorrhoeae containing both pili and OMVs. The technique was compared with the widely used method of isopycnic equilibrium density gradient centrifugation (Johnston \& Gotschlich, 1974) for the purification of outer membranes. The purity of the OMVs was assessed by several criteria. Pili once separated from OMVs by this method were further purified by ultracentrifugation, gel filtration and isoelectric focusing.

\footnotetext{
Abbreviations: CDM, chemically defined medium; LPS, lipopolysaccharide; OMV, outer membrane vesicle; WGA, wheat germ agglutinin.
} 


\section{METHODS}

Gonococci. The BS4 (agar) strain was obtained by passaging the BS strain (Veale et al., 1975) four times through chambers implanted subcutaneously in guinea-pigs followed by one subculture on a complex agar medium (Penn et al., 1976, 1978). Strain BS4 PS (agar) was a 'pure smooth' (non-autoagglutinating) piliated clone (Penn et al., 1980) derived from a single double highlight colony of BS4 (agar) by the procedure described by Parsons et al. (1980) for obtaining a 'pure rough' (autoagglutinating) clone from strain BS4 R. The BS4 PS (agar) strain grown in a CDM (see below) was termed BS4 PS (CDM). BS4 NH (agar) was a no highlight (Penn et al., 1977), colony-forming, non-piliated variant isolated from BS4 PS (CDM), and after growth in CDM was called BS4 NH (CDM). The predominantly piliated BS4 PS (CDM) and the non-piliated BS4 NH (CDM) forms are abbreviated to $\mathrm{SP}^{+}$and $\mathrm{P}^{-}$, respectively.

Growth conditions. The liquid CDM described by Morse \& Bartenstein (1980) was used. One litre volumes of medium in 51 bottles were inoculated at an initial viable count of $2 \times 10^{7}$ cells $\mathrm{ml}^{-1}$ with either BS4 PS (agar) or BS4 NH (agar) strains grown on complex agar medium. The bottles were shaken in air at $37^{\circ} \mathrm{C}$ in an orbital shaker (Gallenkamp Ltd, London, U.K.) at $250 \mathrm{rev} . \mathrm{min}^{-1}$ for $13 \mathrm{~h}$. The yields of $\mathrm{sP}^{+}$and $\mathrm{P}^{--}$were $5 \times 10^{9}$ and 8 $\times 10^{9}$ cells (ml medium $)^{-1}$, respectively. The highlight morphology of the colonies of the organisms recovered from liquid cultures of strain $\mathrm{sP}^{+}$was examined after growth on complex agar medium according to Penn et al. (1977); $30-40 \%$ of the colonies were of the non-piliated, no highlight type, the remainder being the piliated, double highlight type. This formation of a large proportion of non-piliated variants in liquid cultures of the piliated 'smooth' clone could not be prevented.

Extraction of surface antigens. Surface washes of $\mathrm{sP}^{+}$and $\mathrm{P}^{-}$organisms were prepared as described previously (Perera et al., 1980). Gonococci remaining after surface washing were resuspended in $1 \mathrm{M}-\mathrm{LiCl}$ (Leith \& Morse, 1980) to a cell density of $10^{11}$ cells ml $\mathrm{ml}^{-1}$, and shaken in Erlenmeyer flasks with 4-5 glass beads $\mathrm{ml}^{-1}(3 \mathrm{~mm} \mathrm{diam}$.) at room temperature for $2 \mathrm{~h}$ on an orbital shaker at $250 \mathrm{rev}, \mathrm{min}^{-1}$. The volume of the cell suspensions was $30-40 \%$ of the capacity of the flasks. The cells were removed by centrifugation at $10000 \mathrm{~g}$ for $15 \mathrm{~min}$ at $4{ }^{\circ} \mathrm{C}$ and the supernatants ( $\mathrm{LiCl}$ extracts) were stored frozen at $-20^{\circ} \mathrm{C}$.

Preparation of WGA affinity column. WGA, extracted from wheat germ $(1 \mathrm{~kg})$ with $0.05 \mathrm{M}-\mathrm{HCl}$, was concentrated with ammonium sulphate (Nagata \& Burger, 1974) and partially purified by ion exchange chromatography followed by affinity chromatography on chitin (Bloch \& Burger, 1974). The final yield of WGA was $350 \mathrm{mg}$ per $\mathrm{kg}$ of wheat germ. The lectin was coupled to Sepharose 4B as described by Adair \& Kornfeld (1974). Briefly, WGA (100 mg) was dissolved in $50 \mathrm{ml}$ of coupling buffer $\left(0.01 \mathrm{M}-\mathrm{NaHCO}_{3}, \mathrm{pH} 8.3\right.$ with $0.15 \mathrm{M}-\mathrm{NaCl}$ ) containing $0.1 \mathrm{M}-\mathrm{N}$-acetyl-D-glucosamine $(\mathrm{GlcN})$ (Sigma) and to this was added $25 \mathrm{ml}$ (settled volume) of CNBr-activated Sepharose 4B (Pharmacia). After gentle shaking (50 rev. $\mathrm{min}^{-1}$ ) on an orbital shaker at $4{ }^{\circ} \mathrm{C}$ for $13-14 \mathrm{~h}$, the gel was poured into a column $(1.3 \times 25 \mathrm{~cm}$, Chromatography Supplies Ltd). The column was washed sequentially with $50 \mathrm{ml}$ each of coupling buffer, $0.01 \mathrm{M}$-acetate buffer, $\mathrm{pH} 4.0$, containing $0.15 \mathrm{M}$ $\mathrm{NaCl}$ and finally $0.01 \mathrm{M}$-Tris/ $\mathrm{HCl}$ buffer, $\mathrm{pH} 8.5$ containing $0.02 \%\left(\mathrm{w} / \mathrm{v}\right.$ ) $\mathrm{NaN}_{2}$ (Tris/HCl buffer 1). Approximately $85 \%$ of the WGA was bound to Sepharose $4 \mathrm{~B}$ gel ( $4.4 \mathrm{mg}$ protein per $\mathrm{ml}$ of gel).

Purification of pili. A surface wash $(20 \mathrm{ml})$ of strain $\mathbf{s P}^{+}$was applied to the WGA affinity column and washed with Tris/HCl buffer 1 . The effluent $(25-30 \mathrm{ml})$ was collected and checked for the absence of OMVs by (i) crossed affinity electrophoresis with WGA (Perera et al., 1980); (ii) 2DIEP with antiserum to whole gonococci (Penn et al., 1978; Perera et al., 1980) and (iii) electron microscopy (Perera et al., 1980). (The effluent of the surface wash of strain $\mathrm{P}^{-}$was discarded.) Solid $\mathrm{NaCl}$ was added to the effluent to a final concentration of $1 \mathrm{M}$ (Robertson et al., 1977 ) and it was refrigerated at $4{ }^{\circ} \mathrm{C}$ for $14-15 \mathrm{~h}$ to allow aggregation of pili. The aggregated pili were harvested by ultracentrifugation at $80000 \mathrm{~g}$ for $4 \mathrm{~h}$ at $4{ }^{\circ} \mathrm{C}$ and the pellet suspended in $4 \mathrm{ml}$ of Tris/ $\mathrm{HCl}$ buffer $2(\mathrm{Tris} / \mathrm{HCl}$ buffer 1 containing $1 \mathrm{M}-\mathrm{NaCl}$ ).

Samples $(2 \mathrm{ml})$ containing crude pili were then chromatographed on a Sepharose 6B (Pharmacia) column (settled volume, $200 \mathrm{ml}$ ) previously equilibrated with $\mathrm{Tris} / \mathrm{HCl}$ buffer 2 . Fractions collected were monitored for the presence of protein by measuring the $A_{280}$. The aggregated pili present in the first peak were concentrated by ultracentrifugation and the pellet (resuspended in $2 \mathrm{ml}$ of Tris/ $\mathrm{HCl}$ buffer 2) was rechromatographed on the same column. The partially purified pili in the first peak were again harvested by ultracentrifugation, resuspended in $1 \mathrm{ml}$ of distilled water, dialysed against a solution of $1 \%(\mathrm{w} / \mathrm{v})$ glycine for $14-15 \mathrm{~h}$ at $4{ }^{\circ} \mathrm{C}$ (Robertson et al., 1977) and purified further by isoelectric focusing. Preparative isoelectric focusing was carried out in a sucrose gradient of $5-50 \%(\mathrm{w} / \mathrm{v})$ sucrose and $1.5 \%(\mathrm{v} / \mathrm{v})$ ampholines (pH 3-11 or 4-6, LKB). Protein-containing fractions corresponding to a pI value of 5.3 were pooled, dialysed against distilled water for $3 \mathrm{~d}$ at $4{ }^{\circ} \mathrm{C}$ to remove the sucrose, and the pili were harvested by ultracentrifugation after reaggregation with $\mathrm{NaCl}$. The pellet was resuspended in $0.1 \mathrm{M}$-Tris $/ \mathrm{HCl}$ buffer, $\mathrm{pH} 8.5$ containing $0.02 \%(\mathrm{w} / \mathrm{v}) \mathrm{NaN}_{2}(\mathrm{Tris} / \mathrm{HCl}$ buffer 3$)$ and stored frozen in $100 \mu \mathrm{l}$ portions.

Purification of OMVs by affinity chromatography. The column was saturated with OMVs by applying the corresponding $\mathrm{LiCl}$ extract $(20 \mathrm{ml})$. After thorough washing of the column with $300 \mathrm{ml}$ of Tris/ $\mathrm{HCl}$ buffer 1 containing $0.3 \mathrm{M}-\mathrm{NaCl}$, the OMVs bound to the column were eluted with $25 \mathrm{ml}$ of Tris/ $\mathrm{HCl}$ buffer 1 containing 
either $1 \mathrm{M}-\mathrm{NaI}$ (Avrameas \& Ternynck, 1967; Dandliker et al., 1967), or 0.1 M-GlcN or 20-30 mM chitin oligosaccharides. Chitin oligosaccharides were prepared by partial acid hydrolysis of washed chitin (Sigma) according to Raftery et al. (1969) and Capon \& Foster (1970). The neutralized hydrolysate was reacetylated with acetic anhydride (J. P. Ride, personal communication) and was desalted on a Sephadex G-15 (Pharmacia) column and carbohydrate-containing fractions corresponding to $(\mathrm{GlcN})_{6}$ to $(\mathrm{GlcN})_{2}$ were pooled. Chitin oligosaccharides were determined as reducing equivalents (with glucose as standard) by the anthrone method (Trevelyan \& Harrison, 1952). Fractions from the affinity column were monitored for protein by (i) measuring the $A_{280}$ and (ii) the use of a modified Lowry method (Hartree, 1972). Protein-containing fractions with OMVs were pooled and ultracentrifuged at $100000 \mathrm{~g}$ for $1.5 \mathrm{~h}$ at $4{ }^{\circ} \mathrm{C}$ (Beckman L2-65 Preparative Ultracentrifuge). The translucent pellet of OMVs was suspended in Tris/ $\mathrm{HCl}$ buffer 3 at a protein concentration of $5 \mathrm{mg} \mathrm{m}^{-1}$ and stored frozen at $-20^{\circ} \mathrm{C}$ in $100 \mu \mathrm{l}$ portions. In some experiments, purified OMVs of strain $\mathrm{SP}^{+}$were reapplied to the affinity column and repurified as above using chitin oligosaccharides as the desorbent.

Purification of OMVs by density gradient centrifugation. OMVs present in a $\mathrm{LiCl}$ extract $(20 \mathrm{ml})$ of $\mathrm{strain}^{\mathrm{s}} \mathrm{P}^{+}$ were concentrated by ultracentrifugation at $100000 \mathrm{~g}$ for $1.5 \mathrm{~h}$ and the pellet suspended in $3 \mathrm{ml}$ of Tris/ $\mathrm{HCl}$ buffer 3. Samples $(0.2 \mathrm{ml})$ of the pellet were layered on to each of five discontinuous gradients of $4.5 \mathrm{ml}$ of $60-20 \%$ $(w / w)$ sucrose in Tris/ $\mathrm{HCl}$ buffer 3 . The gradients loaded with the samples were ultracentrifuged at $250000 \mathrm{~g}$ for $18 \mathrm{~h}$ at $4{ }^{\circ} \mathrm{C}$ (Type SW 50.1 rotor) (Johnston \& Gotschlich, 1974). Fractions $(0.25 \mathrm{ml})$ were collected by upward displacement with a $60 \%(\mathrm{w} / \mathrm{w})$ sucrose solution, diluted with an equal volume of Tris/ $\mathrm{HCl}$ buffer 3 and monitored for protein by measuring the $\boldsymbol{A}_{280}$. Fractions from a gradient (run simultaneously) with Tris/HCl buffer 3 alone were used to determine the densities which were calculated from the refractive indices. Fractions (from all five gradients) in the peak corresponding to a buoyant density of $1.22 \mathrm{~g} \mathrm{~cm}^{-3}$ were pooled, diluted fourfold with Tris/ $\mathrm{HCl}$ buffer 3 and ultracentrifuged at $100000 \mathrm{~g}$ for $1.5 \mathrm{~h}$ at $4{ }^{\circ} \mathrm{C}$. The pellet of OMVs was suspended in Tris/ $\mathrm{HCl}$ buffer 3 at a protein concentration of $5 \mathrm{mg} \mathrm{ml}^{-1}$ and stored frozen in $50 \mu \mathrm{l}$ portions.

Further purification of OMVs by immunoadsorbent chromatography. An anti-pili-immunoadsorbent column was prepared from antiserum raised to purified pili in guinea-pigs (Dunkin-Hartley; weight approximately $800 \mathrm{~g}$ ). The immunization programme used was as described previously for rabbits (Perera et al., 1980) except that the guinea-pigs received single subcutaneous injections. The column (settled volume, $10 \mathrm{ml}$ ) was prepared by coupling the immunoglobulin G fraction of the antiserum to CNBr-activated Sepharose 4B (Livingston, 1974). A suspension of OMVs $(1 \mathrm{ml})$ of strain $\mathrm{sP}^{+}$purified twice by WGA affinity chromatography was passed through the column which was washed with $\mathrm{Tris} / \mathrm{HCl}$ buffer 1 . Fractions containing protein (monitored by $A_{280}$ ) were pooled, ultracentrifuged at $100000 \mathrm{~g}$ for $1.5 \mathrm{~h}$ and the pellet of OMVs resuspended in Tris/ $\mathrm{HCl}$ buffer 3 as before.

Assessment of purity. Four methods were used: (i) electron microscopy of negatively stained preparations (Perera et al., 1980); (ii) 2DIEP (Penn et al., 1978; Perera et al., 1980) with an anti-gonococcal serum capable of resolving about twelve different antigens; (iii) SDS-PAGE (Laemmli, 1970) with $12 \%(\mathrm{w} / \mathrm{v})$ and $14 \%(\mathrm{w} / \mathrm{v})$ polyacrylamide separating gels for OMVs and pili, respectively and using ovalbumin, bovine serum albumin, $\beta$-lactoglobulin and equine heart cytochrome $c$ as molecular weight standards; (iv) examination of the antibody response in rabbits (Californian; weight approximately $3 \mathrm{~kg}$ ) or guinea-pigs (Dunkin-Hartley; weight approximately $800 \mathrm{~g}$ ) by 2 DIEP with a surface wash of strain $\mathrm{sP}^{+}$. The immunization programme for guinea-pigs was as described above.

\section{RESULTS}

\section{Purification of pili}

The effluent obtained by applying a surface wash of strain $\mathrm{sP}^{+}$to the WGA affinity column failed to react with WGA in crossed affinity electrophoresis and the only particulate antigens visible under the electron microscope were pili. Examination of the effluent by 2DIEP with antiserum to whole gonococci failed to detect immunoprecipitate $c$.

After chromatography on a Sepharose $6 \mathrm{~B}$ column in the presence of buffer containing $1 \mathrm{M}-\mathrm{NaCl}$, electron microscopy showed that most of the pili were associated with the first peak (in the void volume), while most of the non-particulate antigens were in the second peak. The $A_{280}$ values for fractions between the two peaks failed to reach the baseline value; however, rechromatography of the first peak removed contaminating antigens from pili and the $A_{280}$ values for fractions between the peaks reached the baseline value.

Preliminary isoelectric focusing experiments with a $\mathrm{pH}$ range of 3-11 indicated that the $\mathrm{pI}$ of pili obtained by gel filtration was between 5 and 6 . In the narrow $\mathrm{pH}$ range (4-6), pili formed a broad peak at a pI value of $5 \cdot 3$. The yield of purified pili was approximately $1-2 \mathrm{mg}$ from $20 \mathrm{ml}$ of surface wash (from approximately $2 \times 10^{12}$ gonococci). In an assessment of 
purity, electron microscopy revealed pili with no contaminating OMVs (Fig. 1a), and examination by 2DIEP with antiserum to whole gonococci produced the characteristic immunoprecipitate $a$ (Fig. $1 \mathrm{~b}$ ). The SDS-PAGE pattern showed single diffuse bands corresponding to a pilin subunit with an apparent molecular weight of 22500 and the
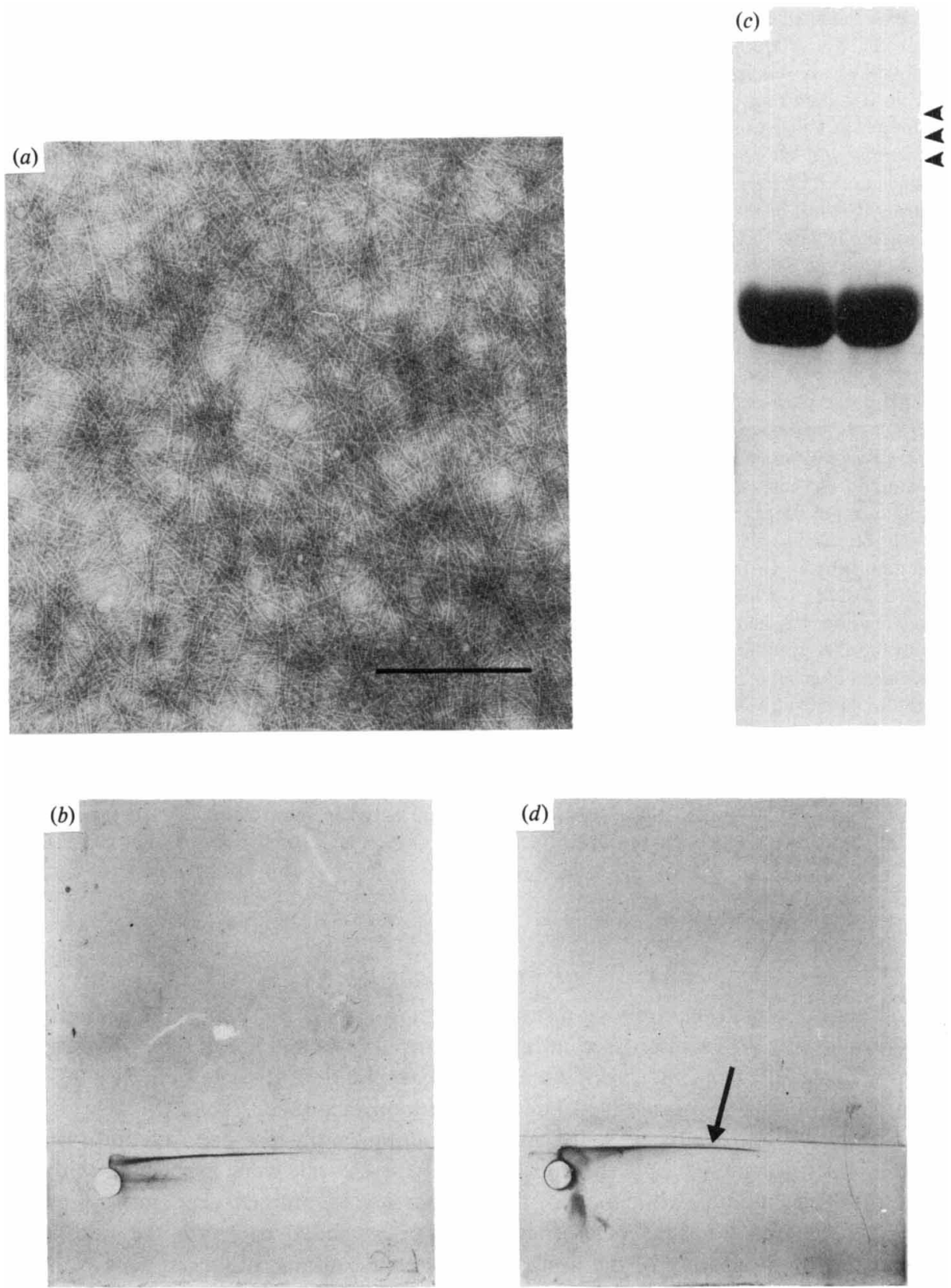

Fig. 1. Assessment of purity of purified pili of strain $\mathrm{sP}^{+}$. (a) Electron micrograph (the bar marker represents $0.2 \mu \mathrm{m}$ ). (b) 2DIEP pattern with antiserum to whole gonococci. (c) SDS-PAGE pattern of two preparations of purified pili (solubilized at $100{ }^{\circ} \mathrm{C}$ for $5 \mathrm{~min}$ ). The arrow heads mark the expected position of major outer membrane proteins. $(d)$ Antibody response (in guinea-pigs) to purified pili as analysed by 2DIEP with a surface wash (the arrow indicates the second immunoprecipitate). 
preparations were free of outer membrane proteins (Fig. 1c). Guinea-pigs immunized with purified pili produced antisera which when examined by 2DIEP with a surface wash of strain $\mathrm{sP}^{+}$(Fig. $1 d$ ) showed immunoprecipitate $a$ as well as a faint second immunoprecipitate (arrowed).

\section{Purification of OMVs by WGA affinity chromatography; a comparison with sucrose density gradient centrifugation}

While effluents obtained by applying a surface wash to the affinity column did not contain OMVs, application of $\mathrm{LiCl}$ extract produced an effluent which contained some OMVs when examined under the electron microscope. Although OMVs remaining bound to the column were successfully eluted with chaotropic $1 \mathrm{M}-\mathrm{NaI}$, repeated use of $\mathrm{NaI}$ decreased the binding capacity, and hence an alternative eluant was sought. While GlcN failed to dissociate the antigen, $\mathrm{GlcN}$-(chitin) oligosaccharides were as effective as $\mathrm{NaI}$, and their repeated use did not decrease the binding capacity of the column. Both $\mathrm{NaI}$ and chitin oligosaccharides produced comparable yields of outer membrane proteins, i.e. 8-10 $\mathrm{mg}$ from $20 \mathrm{ml}$ of surface wash and from $20 \mathrm{ml}$ of $\mathrm{LiCl}$ extract (from approximately $2 \times 10^{12}$ gonococci).

Electron microscopy of purified OMVs showed no contamination by any other particulate antigen (Fig. $2 a$ ) and the material produced only one immunoprecipitate arc (Fig. $2 b$ ) in 2DIEP with antiserum to whole gonococci. The stained material beneath the immunoprecipitate (Fig. $2 b$, arrow) was detectable in gels with pre-immune serum and without serum in the second dimension. Purified vesicles eluted with $\mathrm{NaI}$ and examined (at $80 \mu \mathrm{g}$ of protein) by SDS-PAGE revealed the principal outer membrane protein, protein I $(36.3 \mathrm{kDal})$, and at least two heat-modifiable proteins, II $(28 \mathrm{kDal})$ and II $(26 \mathrm{kDal})$ (Fig. 3, lane 1) which were heat modified to II* $(34 \cdot 5 \mathrm{kDal})$ and II* $(31 \mathrm{kDal})$, respectively (Fig. 3, lane 2$)$, on heating to $100{ }^{\circ} \mathrm{C}$. Minor outer membrane proteins were also detectable. Since $30-40 \%$ of the colonies
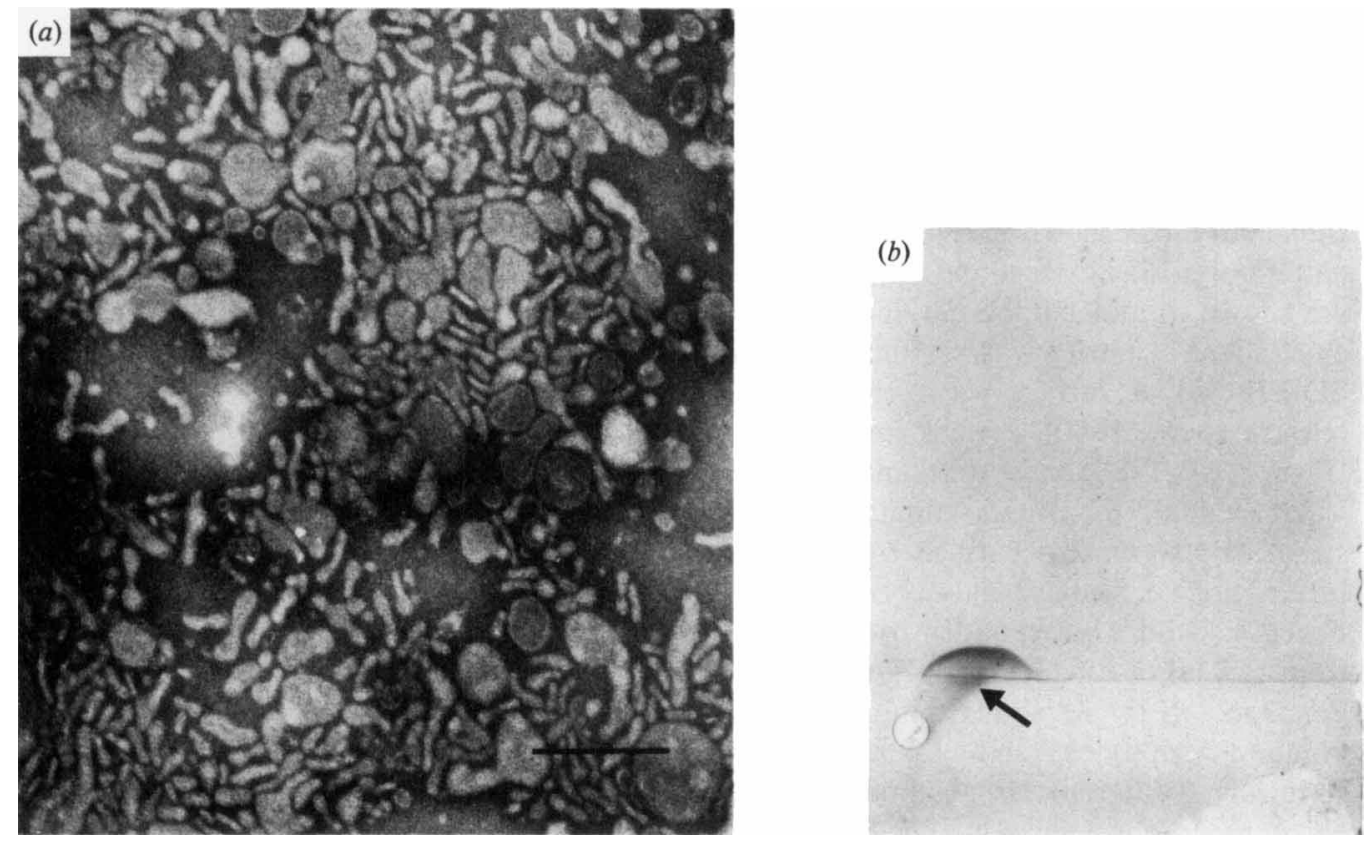

Fig. 2. OMVs of strain $\mathrm{SP}^{+}$purified by WGA affinity chromatography. (a) Electron micrograph (negative stain); the bar marker represents $0.2 \mu \mathrm{m}$ and $(b)$ 2DIEP pattern with antiserum to whole gonococci (the arrow indicates an artefact detectable without serum). 


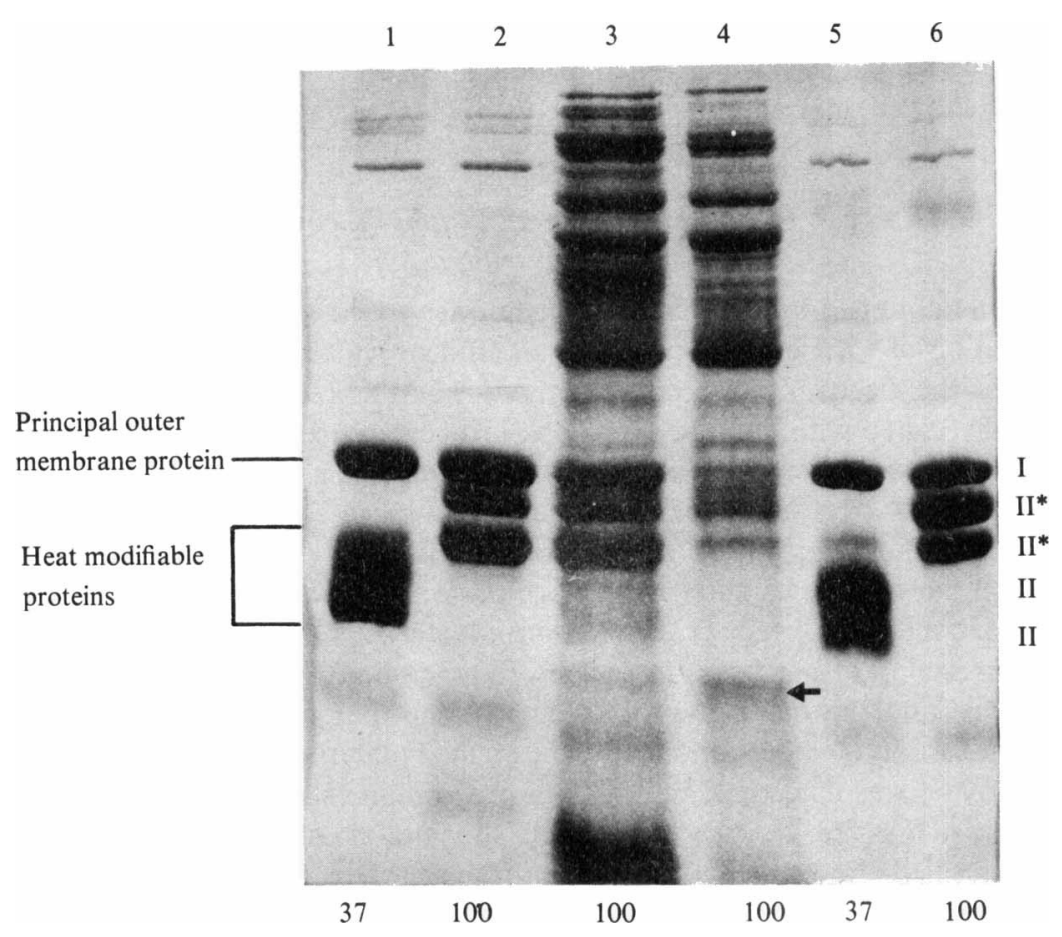

Fig. 3. SDS-PAGE patterns of crude antigen extracts and purified OMVs of strain $\mathrm{SP}^{+}(37$, solubilized at $37^{\circ} \mathrm{C}$ for $2 \mathrm{~h} ; 100$, solubilized at $100^{\circ} \mathrm{C}$ for $\left.5 \mathrm{~min}\right)$. Lanes $1-6$, respectively, are $(1,2)$ OMVs purified by WGA affinity chromatography, (3) lithium chloride extract, (4) surface wash and $(5,6)$ OMVs prepared by sucrose density gradient centrifugation (the arrow indicates a pilin band).

recovered from liquid cultures of strain $\mathrm{sP}^{+}$were of the non-piliated type, OMVs of the variant $\mathrm{P}^{-}$were also purified by WGA affinity chromatography using $\mathrm{NaI}$ as eluant, and SDS-PAGE revealed a similar pattern to that shown in Fig. 3, lanes 1 and 2. OMVs of strain $\mathrm{sP}^{+}$eluted with chitin oligosaccharides produced a 2DIEP pattern and a protein profile similar to those shown in Fig. $2(b)$ and Fig. 3, lanes 1 and 2, respectively. The SDS-PAGE pattern of a $\mathrm{LiCl}$ extract and a surface wash of strain $\mathrm{sP}^{+}$(Fig. 3, lanes 3 and 4, respectively) are shown to indicate the purification achieved by WGA affinity chromatography. The final assessment of purity was by immunization of rabbits, and examination of the antiserum by 2DIEP with a surface wash of strain $\mathrm{sP}^{+}$showed immunoprecipitate $c$ (due to OMVs) (Perera et al., 1980), a weak immunoprecipitate $a$ due to contaminating anti-pili antibody (Penn et al., 1980) and a third immunoprecipitate (figure not shown).

To evaluate the WGA affinity chromatography method, OMVs from a $\mathrm{LiCl}$ extract of strain $\mathrm{sP}^{+}$were also purified by isopycnic sucrose density gradient centrifugation, which produced two visible bands corresponding to buoyant densities of 1.18 and $1.22 \mathrm{~g} \mathrm{~cm}^{-3}$. Fractions with a buoyant density of $1.22 \mathrm{~g} \mathrm{~cm}^{-3}$ yielded $3-4 \mathrm{mg}$ of outer membrane proteins from $6-8 \mathrm{ml}$ of $\mathrm{LiCl}$ extract. The vesicles when analysed by 2DIEP with antiserum to whole gonococci (Fig. 4) showed immunoprecipitates $c$ and $a$ (arrow), and two further faint immunoprecipitates (arrow heads). The shape of the main immunoprecipitate, $c$, was somewhat different from that obtained with vesicles purified by WGA affinity chromatography (Fig. $2 b$ ). The SDS-PAGE pattern of vesicles purified by density gradient centrifugation (Fig. 3, lanes 5 and 6) was similar to that of those purified by WGA affinity chromatography (Fig. 3, lanes 1 and 2). A protein band corresponding to pilin was not detectable in either preparation of vesicles. 


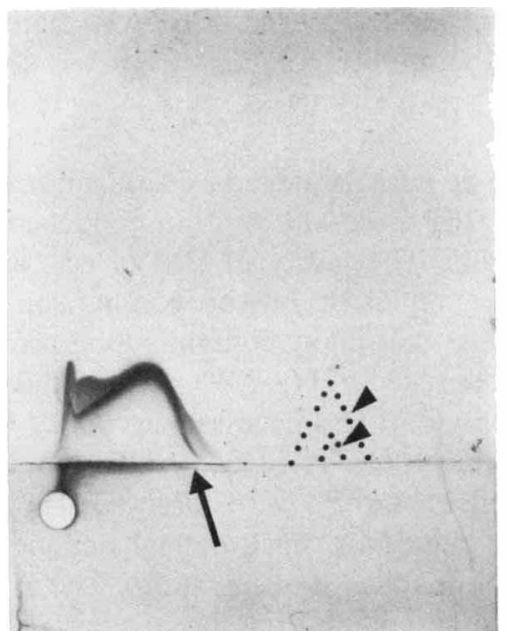

Fig. 4

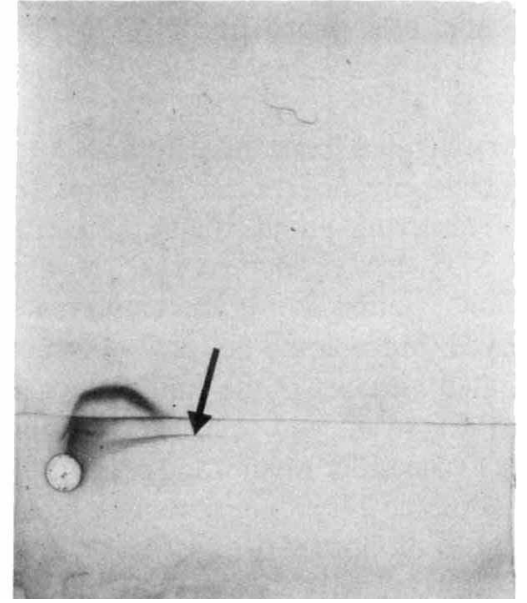

Fig. 5

Fig. 4. 2DIEP pattern of OMVs of strain $\mathrm{sP}^{+}$purified by sucrose density gradient centrifugation (the arrow indicates immunoprecipitate $a$; the arrow heads indicate other faint immunoprecipitates).

Fig. 5. Antibody response (in guinea-pigs) to highly purified OMVs of strain $\mathrm{sP}^{+}$as analysed by $2 \mathrm{DIEP}$ with a surface wash of the same strain (the arrow indicates the second immunoprecipitate).

\section{Attempts to further purify OMVS}

Repurification of vesicles by affinity chromatography led to no significant change in the yield of outer membrane proteins. Both electron microscopy and 2DIEP with antiserum to whole gonococci again indicated a high degree of purity (as in Figs $2 a$ and $2 b$ ). Repurification had no effect on the SDS-PAGE protein profile. Immunization of guinea-pigs with the repurified OMVs produced antisera with a similar specificity to those produced by rabbits against vesicles purified once by affinity chromatography.

OMVs repurified by WGA affinity chromatography were finally passed through an anti-pili-Sepharose 4B immunoadsorbent column; this did not significantly affect the yield of outer membrane proteins. The OMVs were pure as judged by electron microscopy and 2DIEP, and SDS-PAGE produced the characteristic profile of outer membrane proteins. Antisera from guinea-pigs immunized with these OMVs produced immunoprecipitate $c$ and a second weak immunoprecipitate (arrowed) (Fig. 5) in 2DIEP with a surface wash of strain $\mathrm{sP}^{+}$. The stained material between the two immunoprecipitates was not detectable with other antisera and was therefore not regarded as an immunoprecipitate. These antisera failed to react with purified pili.

\section{DISCUSSION}

Pili separated from OMVs by the lectin method and purified by ultracentrifugation, gel filtration and isoelectric focusing, appeared homogeneous by electron microscopy, 2DIEP and SDS-PAGE. However, the antibody response to purified pili showed the presence of a weak second immunoprecipitate in addition to the main immunoprecipitate, $a$. Observations to be published elsewhere indicated that this second immunoprecipitate was probably due to 'rough' pili (from autoagglutinating 'rough' gonococci; Penn et al., 1980), resulting from either cross-reacting antibody (elicited by antigen $a$ ) or contamination of purified antigen $a$ by traces of 'rough' pili. 
In the purification of the OMVs, chitin oligosaccharides proved effective, whereas GlcN was unsuitable as it failed to elute OMVs from the affinity column. It is likely that chitin oligosaccharides had a higher affinity than GlcN for WGA (Allen et al., 1973; Nagata \& Burger, 1974).

The OMVs eluted from the column appeared to be pure as judged by electron microscopy and produced only one immunoprecipitate in 2DIEP gels with an anti-gonococcal serum capable of resolving about twelve different antigens. The purity of OMVs was difficult to assess by SDS-PAGE due to their biochemical complexity, but by comparison with the electrophoretic patterns of crude extracts it was clear that many contaminating proteins had been removed. Since liquid cultures of strain $\mathrm{sP}^{+}$consisted of $60-70 \%$ piliated and $30-40 \%$ of non-piliated variants at the end of the growth period, it was necessary to purify OMVs of the variant $\mathbf{P}^{-}$strain and then examine the protein profile by SDS-PAGE. No significant differences in the other membrane protein profile of $\mathrm{sP}^{+}$and $\mathrm{P}^{-}$were observed. The detection of heat-modifiable outer membrane proteins was interesting since mainly opaque colonies were produced by both $\mathrm{SP}^{+}$and $\mathrm{P}^{-}$(V. Y. Perera, unpublished observation). The association of similar proteins with gonococci producing opaque colonies has been reported by other workers (Swanson, 1978; Lambden \& Heckels, 1979).

The WGA affinity chromatography method was compared with the sucrose density gradient centrifugation method for purifying OMVs. When examined by 2DIEP, the latter yielded OMVs which showed four immunoprecipitates, two of which corresponded to antigens $c$ and $a$ formed by OMVs and pili, respectively. The slight distortion of the shape of immunoprecipitate $c$ may have been caused by the high concentration of sucrose. Thus in contrast with OMVs purified by affinity chromatography which exhibited a single immunoprecipitate, sucrose density gradient centrifugation did not produce serologically pure outer membranes.

The SDS-PAGE pattern of OMVs purified by density gradient centrifugation was somewhat variable but was essentially similar to that of OMVs purified by affinity chromatography: neither preparation appeared to be grossly contaminated with foreign proteins. Absence of the pilin band in gels containing samples of OMVs purified by density gradient centrifugation indicated that SDS-PAGE was not as sensitive as 2DIEP in detecting low levels of pilin, probably because of the poor staining properties of this protein with Coomassie blue. (The minimum quantity of pili detectable by staining was about $15 \mu \mathrm{g}$, compared with $1 \mu \mathrm{g}$ of ovalbumin - unpublished observation.)

The method of WGA affinity chromatography was better than sucrose density gradient centrifugation for obtaining serologically pure OMVs free of contaminating pili and other antigens. A second advantage was that the WGA affinity chromatography method was easier to perform and could easily be scaled up for large scale production of OMVs.

Though the OMVs purified by WGA affinity chromatography were serologically pure as analysed by 2DIEP, immunization of rabbits with this material produced antisera which contained anti-pili antibody. Low levels of contaminating pili (possibly entrapped in vesicles or groups of vesicles) must therefore have been present in such preparations of OMVs. The degree of contamination with pili was clearly below the limit of sensitivity of the 2DIEP technique. (The minimum of pili required to produce a visible immunoprecipitate $a$ was approximately $0.5 \mu \mathrm{g}$ and a quantity of OMVs containing $100 \mu \mathrm{g}$ of protein was examined in this test.) This also indicated the high immunogenicity of gonococcal pili. Analysis of the antibody response to the purified material was therefore the most sensitive method of detection of low levels of contaminating pili in OMVs purified by affinity chromatography.

An attempt to remove traces of contaminating pili from OMVs by repeating WGA affinity chromatography was unsuccessful since the repurified OMVs still elicited antibody to pili in guinea-pigs. OMVs (purified twice by affinity chromatography) were finally passed through an anti-pili-immunoadsorbent column for removing traces of pilus protein. Guinea-pigs immunized with this material produced antibodies to OMVs and to a second antigen when 
tested by 2DIEP against a surface wash of strain $\mathrm{sP}^{+}$. This second immunoprecipitate appeared not to be due to contaminating anti- $a$ (pilus) antibody for essentially two reasons: (i) the shape of the immunoprecipitate was different from that of antigen a (Penn et al., 1980) and (ii) the antisera failed to react with purified pili of strain $\mathrm{sP}^{+}$. The possibility remains, however, that the contaminating antibody may have been directed against pili of autoagglutinating 'rough' variants (Parsons et al., 1979; Penn et al., 1980) due to the presence of a small amount of these pili in OMV preparations.

We thank Dr J. P. Ride for helpful discussion on lectin biochemistry, and Mrs J. D. Lichfield and Mr D. Ruffles for help with electron microscopy and photography.

\section{REFERENCES}

Adair, W. L. \& Kornfeld, S. (1974). Isolation of the receptors for wheat germ agglutinin and the Ricinus communis lectins from human erythrocytes using affinity chromatography. Journal of Biological Chemistry 249, 4696-4704.

Allen, A. K., Neuberger, A. \& Sharon, N. (1973). The purification, composition and specificity of wheat germ agglutinin. Biochemical Journal 131, $155-162$.

Allen, P. Z., Connelly, M. C. \& Apicella, M. A. (1980). Interactions of lectins with Neisseria gonorrhoeae. Canadian Journal of Microbiology 26 , 468-474.

Avrameas, S. \& Ternynck, T. (1967). Use of iodide salts in the isolation of antibodies and the dissolution of specific immune precipitates. Biochemical Journal 102, 37C-39C.

Bloch, R. \& Burger, M. M. (1974). Purification of wheat germ agglutinin using affinity chromatography on chitin. Biochemical and Biophysical Research Communications 58, 13-19.

Buchanan, T. M. (1975). Antigenic heterogeneity of gonococcal pili. Journal of Experimental Medicine 141, 1470-1475.

CAPON, B. \& Foster, R. L. (1970). The preparation of chitin oligosaccharides. Journal of the Chemical Society C, 1654-1655.

Dandliker, W. B., Alonso, R., De Saussere, V. A., Kierszenbaum, F., Levison, S. A. \& Schapiro, H. C. (1967). The effect of chaotropic ions on the dissociation of antigen antibody complexes. Biochemistry 6, 1460-1467.

FrasCH, C. E. (1980). Role of lipopolysaccharide in wheat germ agglutinin-mediated agglutination of Neisseria meningitidis and Neisseria gonorrhoeae. Journal of Clinical Microbiology 12, 498-501.

HARTREe, E. F. (1972). Determination of protein: a modification of Lowry method that gives a linear photometric response. Analytical Biochemistry 48. $422-427$.

hayman, M. J., Skehel, J. J. \& Crumpton, M. J. (1973). Purification of virus glycoproteins by affinity chromatography using Lens culinaris phytohaemagglutinin. FEBS Letters 29, 185-188.

Johnston, K. H. \& Gotschlich, E. C. (1974). Isolation and characterisation of the outer membrane of Neisseria gonorrhoeae. Journal of Bacteriology 119, 250-257.

Johnston. K. H., Holmes, K. K. \& Gotschlich, E. C. (1976). The serological classitication of
Neisseria gonorrhoeae. I. Isolation of the outer membrane complex responsible for serotypic specificity. Journal of Experimental Medicine 143, 741-758.

LAEMMLI, U. K. (1970). Cleavage of structural proteins during the assembly of the head of bacteriophage $T_{4}$. Nature, London 227, 680-685.

Lambden, P. R. \& Heckels, J. E. (1979). Outer membrane protein composition and colonial morphology of Neisseria gonorrhoeae strain P9. FEMS Microbiology Letters 5, 263-265.

LEITH, D. K. \& MORSE, S. A. (1980). Effect of dissolved oxygen on outer membrane protein composition of Neisseria gonorrhoeae grown in continuous culture. FEMS Microbiology Letters 7, 191-194.

Livingston, D. M. (1974). Immunoaffinity chromatography of proteins. Methods in Enzymology 34, 723-731.

Mintz, G. \& Glaser, L. (1979). Glycoprotein purification on a high-capacity wheat germ lectin affinity column. Analytical Biochemistry 97, 423427.

Morse, S. A. \& Bartenstein, L. (1980). Purine metabolism in Neisseria gonorrhoeae: the requirement for hypoxanthine. Canadian Journal of Microbiology 26, 13-20.

NagatA, Y. \& Burger, M. M. (1974). Wheat germ agglutinin. Molecular characteristics and specificity for sugar binding. Journal of Biological Chemistry 249, 3116-3122.

Parsons, N. J., Penn, C. W., Veale, D. R. \& Smith, H. (1979). More than one antigen contributes to the immunogenicity of Neisseria gonorrhoeae in the guinea pig chamber model. Journal of General Microbiology 113, 97-104.

Parsons, N. J., Penn, C. W., Veale, D. R. \& Smith, H. (1980). The complexity of immunogenicity of Neisseria gonorrhoeae in the guinea pig subcutaneous chamber model. Journal of General Microbiology 118, 523-527.

Penn, C. W., Sen, D., Veale, D. R., Parsons, N. J. \& SмiтH, H. (1976). Morphological, biological and antigenic properties of Neisseria gonorrhoeae adapted to growth in guinea pig subcutaneous chambers. Journal of General Microbiology 97, 35-43.

PenN, C. W., Veale, D. R. \& Smith, H. (1977). Selection from gonococci grown in vitro of a colony type with some virulence properties of organisms 
adapted in vivo. Journal of General Microbiology $100,147-158$.

Penn, C. W., Parsons, N. J., Veale, D. R. \& Smith, H. (1978). Correlation with different immunotypes of gonococcal antigens associated with growth in vivo. Journal of General Microbiology 105, 153157.

Penn, C. W., Parsons, N. J., Veale, D. R. \& Smith, H. (1980). Antigenic heterogeneity associated with pilus aggregation and autoagglutinability in Neisseria gonorrhoeae. Journal of General Microbiology 121, 195-202.

Perera, V. Y., Penn, C. W. \& Smith, H. (1980). The use of specific antiserum induced by lectin-antigen complexes to investigate the outer membrane antigens of Neisseria gonorrhoeae. Journal of Immunological Methods 37, 175-184.

RAFTERY, M. A., RAND-MeIR, T., Dahlquist, F. W., Parsons, S. M., Borders, C. L., Wolcott, R. G., BERANEK, W. \& JAO, L. (1969). Separation of glycosaminoglycan saccharide and glycoside mixtures by gel filtration. Analytical Biochemistry 30, $427-435$.

Robertson, J. N., Vincent, P. \& Ward, M. E. (1977). The preparation and properties of gonococcal pili. Journal of General Microbiology 102 , 169-177.
Schaefer, R. L., Keller, K. F. \& Doyle, R. J. (1979). Lectins in diagnostic microbiology: use of wheat germ agglutinin for laboratory identification of Neisseria gonorrhoeae. Journal of Clinical Microbiology 10, 669-672.

SwaNSON, J. (1978). Studies on gonococcus infection. XII. Colony color and opacity variants of gonococci. Infection and Immunity 19, 320-331.

Trevelyan, W. E. \& Harrison, J. S. (1952). Studies on yeast metabolism. I. Fractionation and microdetermination of cell carbohydrates. Biochemical Journal 50, 298-303.

Van EtTen, R. L. \& Saini, M. S. (1977). Preparation of homogeneous human prostatic acid phosphatase using concanavalin-A Sepharose 4B. Biochimica et biophysica acta 484, 487-492.

Veale, D. R., Smith, H., WitT, K. A. \& Marshall, R. B. (1975). Differential ability of colonial types of Neisseria gonorrhoeae to produce infection and an infiammatory response in subcutaneous perforated plastic chambers in guinea-pigs and rabbits. Journal of Medical Microbiology 8, 325-335.

VRetblad, P. \& HJorth, R. (1977). The use of wheat-germ lectin sepharose for the purification of human haemopexin. Biochemical Journal 167, $759-764$. 